\title{
Thought and Research on Chinese Sports from the Perspective of Confucian Philosophy
}

\author{
Yang Xiuchang \\ Pingdingshan Institute of Education, Pingdingshan Henan China, 467000
}

\begin{abstract}
This article conducts a research on Chinese sports under Confucian philosophy from the perspective of social value that ancient sports sought, development limitation for ancient physical morality and legal system, and development direction of Chinese sports. It also makes an analysis of the promotion and restraint of traditional Confusion culture on Chinese sports, and seeks many valuable factors such as the integration of social and class nature deeply contained in Chinese sports, improvement of physical supervision mechanism and legal system, as well as personal humanistic quality. This article will provide available ideology resources for sustainable development of modern sports, aiming at settling the current problems therein.
\end{abstract}

Key word: Chinese sports; Confusion culture; "benevolence”, “courtesy”; Modern value

\section{Foreword}

"Certain ideology, culture and values are produced by certain social economy and politics." Chinese traditional culture is a reflection of Chinese autocratic social economy relation and political relation. In the long-term feudal society in China, closed and decentralized natural economy was always the main production mode where the ideology of consanguinity and family ethics were highlighted in Chinese traditional culture, and spread over the whole society, which required the establishment of a polite, orderly and harmonious personal dependence relation, for the purpose of maintaining the stability of feudal society. Chinese ancient sports was produced right in that cultural background, and it may be exacter to say it had been a political tool for etiquette and moral education than was profoundly influenced by ethic- or political-type culture. Chinese ancient sports overemphasized its ethic and political function so that weakened the due competitive and fierce nature for athletic sports. Then, this trend was further amplified by close combination with military affairs, religion, medicine, etc., which made it develop into what was totally different from western sports---- "philosophic sports".

This article conducts a research on Chinese sports under Confusion culture, and makes an analysis of the promotion and restraint of traditional Confusion culture on Chinese sports. It also seeks social and class nature deeply contained in Chinese sports, and thus to improve sports supervision mechanism and legal system, as well as personal humanistic quality. This article will provide available ideology resources for sustainable development of modern sports, aiming at settling the current problems therein.

\section{Chinese Sports Culture and Confusion Philosophy}

\subsection{Sport Culture}

In Chinese language, a saying in the Book of Changes that goes "Observe the operating law of nature to see the time alteration, and observe the humanities relation to civilize people all over the world." is the source of culture concept. Humanities represent the creations by human beings in the world, and they reform the state of "world" through their "civilization". It emphasizes that only the reform and cultivation of society, and civilization of human himself under the cultural creation process can make a human be a real human being, which is called "Difficulty is the nurse of greatness".

In Encyclopedia of China (Philosophy Vol.), culture is defined as: "Culture consists of abilities and achievements gained by humans through the process of social practice.” The broad and narrow sense of culture are different: Humans material and spiritual production abilities and all material and spiritual productions belong to broad sense of culture; Spiritual production abilities and its productions, including all aspects of knowledge and facilities such as form of consciousness, science, education, art, literature, sports, sanitation, etc., as well as politic thoughts and morality, world view, etc. that differ from consciousness comprise the narrow sense of culture. Culture is characterized by its symbolism, inheritance, complexity, contemporaneity, transpersonalism, non-hereditary, etc.

Sport is one of the social activities that created by humans, so it represents one kind of culture. It has all features of culture, not only involving physical system like external pattern of physical activities, facilities and 
equipment, but also the internal consciousness, behavioral norms and values. The in-depth content of these ideologies, such as sports ethics, the Olympic Spirit and Creed, have become a part of common ideals for humans.

Sports culture is the integration of sports system, spirit and material culture, generally including understanding, emotion, ethics, ideal, system, value and material condition of sports. It is a kind of cultural basis in social ideology, and was hard to be separated from military affair, medicine, entertainment, education and religion in primitive and feudal society, for which sports failed to form an independent system to win a space among many other cultures in the long course of human history. In modern times, the increasing popularity of Olympic Games over the globe, especially the popularization of sports, enables sports to bring extensive and profound influence on politics, economy and society. Any culture cannot replace the function of sports culture. Finally, sports culture, as an independent cultural type, produces a wide range of social and cultural values in modern society, and becomes an essential part of contemporary culture.

\subsection{Sports Ethics and Morality}

Ethics generally is considered as a synonym of morality because they hold the same etymology and meaning. Ethics originates from Greek, meaning character and temperament, as well as custom and habits. Morality is derived from Latin, meaning character and custom. They both signify the external habits and custom, as well as the morality and character.

However, in China, ethics and morality have different meanings. Ethics and morality appeared independently at their earliest stage, as in "Lun,means the understanding order of people and things". Therefore, Lun is a definition of interrelationships among people. Li originally came as a verb, meaning "jade cutting”. A saying in Strategies of the Warring States goes: "The jade that has not been processed is called Uncut Jade...Although jade is very hard, but it'll finally be a diamond only if it is been cut and produces Li”. Thereafter, $\mathrm{Li}$ is extended to the meaning of principle and norm.

Lun Li(Ethics), literally means sequence and order of things. In the Books of Rites--- Yueli, a saying goes: "Music is the same as ethics.", and Zhu said: "Lun,means classes; Li, means classification.”, and after that, Lun Li (Ethics) is specially used for indicating principles about human relations. But what is the principle of human relations? Human relations, on one hand, it means: "There are many kinds of people in the world. They have their own paths but the same goals, and have common desires but the different understanding of them, which sum up as the life mode." and on the other hand, it means: "A sovereign that violates the rules of human relations and conducts brutal act will face the downfall of his nation within ten years." For short, human relations are the seniority existing among people, and the principle and norm that people shall observe when dealing with interrelationships among different people.
Thus, we can get the concept of sports ethics, which will be the human relations established during sports process, and the principles people shall observe when dealing with those relations, such as "fair, righteous and open”; "Swifter, Higher and Stronger”; "Honest, sincere and true", etc.. So, we can say that sports ethic category is a summary of various moral norms involved in relationships among referees, coaches, athletes, sports lovers, individuals and teams.

In Chinese ethics history, morality is mainly about adjustment of human relations and code of conduct, and sometimes the evaluation of good and evil, individual quality, cultivation and ideal state for people. Therefore, morality may be defined as follows: Morality is a special social ideology of superstructure determined by economic foundation, and also a code of conduct that has good and evil value attributes and is maintained by public opinion, traditional custom and innermost belief. While sports morality means the subjectivity spirit with which people participating in sports internalize the "moral behaviors" buried in sports ethics to be their individual characters and qualities, then pursue morality by their self-discipline conducts and try to surpass themselves in truly honest and fair sports activities.

Sports ethics and morality are different in terms of research objects, levels and contents: Sports ethics emphasize the relations among people and society, interpersonal relations, orders, and principles and patterns they shall observe; Sports morality focuses on mind cultivations of subjects, and on purifying personalities and souls, as well as improving culture of mind and body. We shall, from the depth and breadth development of sports ethics theoretical research, hold a facts-based and scientific spirit to distinguish sports ethics from sports morality so that the two concepts will not be mistakenly used or mixed together.

\section{Sports Ethical Thoughts of Confusion Culture}

Confusion ethical thoughts are represented by Confucius, Mencius and Xunzi. Confucius was the founder of Confusion ethical thoughts, and since the Western Zhou Dynasty, he had focused on "humanities" tradition of human affairs and rule of virtue, summarized the moral thoughts development since the Spring and Autumn Period, which led to the establishment of moral category system that took "benevolence" and "courtesy" as its core for dealing relationships among different people. Besides, he proposed values based on morality, a political theory on rule of virtue, an educational theory on moral culture and a cultivation theory on selfcultivation-to-make-others-happy, which laid a solid foundation for Confusion ethics.

Confucius is a great educationist and ideologist in ancient China. His educational and ethical thoughts reflect many of the sports ethical thoughts. Confucius educational contents include the Book of Songs for expression, the Book of History for documentation, Li Jing for standardization, the Book of Music for harmonization, the Book of Changes for transformation and Spring and Autumn Annals for measurement." All the above show that Confucius laid emphasis on 
morality and intelligence over military sports. He opposed to wars and held that military sports shall serve the benevolence, justice, courtesy and music which shall otherwise be taken to rule the world. Courtesy and morality were very important in archery matches. Confucius Sayings Collected from His Family said that Confucius was watching a village archery, and found the due courtesy was not observed. Angry so much, he sighed and led his students to conduct a demonstrative archery performance. There were so many people watching at the beginning. Then Confucius repeatedly told Zilu and other two students only friendly teenagers, young adults with filial piety, and studious and courteous elders could watch their archery performance. Though at last, almost nobody was left to see this match but Confucius was not disappointed, and otherwise complimented Zilu and other two students on their presiding. The archery result was seen by Confucius as a kind of political treatment, and he took moral character and political status as decisive conditions as to whether one could engage in or watch the archery. Courtesy, rather than skills, was key for an archery. Confucius insisted on "Force penetrating the skin target is not the main point of archery", because he thought archery should focus on whether one could hit the target instead, and contended that a good archery must be fair and just, as well as have a clear goal.

So, what attitude should one have to engage in a match? Confucius thought: There's no need for a man with high character to fight for other matters. He can strive to be the winner in an archery, but shall be modest during the whole match, and shall pay attention to his moral cultivation, bowing and scraping before participation, and shall exchange toasts after match. To put up a fight for victory in a match is the proper choice for noble people, and only skilled and moral people can hit the target. Immoral one is impossible to take part in a match, and will never hit the target even if he is in this match. Whether you will be successful in target hitting is totally decided by ideology and morality, which, of course, belongs to the point of view from idealism. Confucius also thought force must affiliate to benevolence and courtesy, from which we can see that Confucius much highlighted the service of sports for courtesy and morality, i.e. for ruling class and politics. Although this ideology and practice of Confucius seriously harmed the development of archery, and even rulers hated this trivial formalities for archery, his thoughts of having sports cultivate the ideology and morality actually had a positive effect on understanding of sports educational functions.

\section{Shape Cultural Guidance of Social Sports and Highlight Dialectical Relations between Morality and Benefit}

\section{1 "To Value Morality above Benefit", Cultiva- tion to Improve Personal Quality}

Ethical and moral ideas of "Benevolence" that advocated by Confucians is their core and code of conduct for self-improvement, and also an effective way to realize cultivation and longevity. In the Analects--
Yong Ye, Confucius proposed a view point of "Benevolence leads to longevity", reflecting an internal connection of mind cultivation and health and longevity, which laid a solid cultural foundation for breathing technique, health promotion and Yoga that are passed on till now. In cultivation aspect, he also highlighted "The Master said, "The mind of the superior man is conversant with morality; the mind of the mean man is conversant with benefit." Consideration and judgment "Morality" and "Benefit" indicates that sports emphasize personal pursuit of ethical value and social value of sports ethics. "Morality" is a conceptual category, and "Morality takes priority" highlight that the realization of self-value is in compliance with moral principle, and the self-seeking goal shall be achieved in an allowed scale. "Riches and honors acquired by immorality, are to me as a floating cloud.”

\subsection{Humanistic Environment that Purify the Sports}

Facing the temptation of fame, and moral decline of sports, the slow reform of sports legal system appears to give covert priority to championitis and gold medals. While Confucians laid much emphasis on moral cultivation, thinking the good moral qualities shall rely not only on education from society and family, but also on personal moral cultivation. Cultivation comes before family regulations, family regulations before state ruling, and state ruling before creation of a peaceful world. From the emperor to civilian, cultivation shall always be the basis. Confucians attached importance to the cultivation and its necessity, and also elaborated on the contents, methods and routes of moral cultivation, such as mistake correction, emphasis on behavior and action, restraining in privacy and self-communion, which still deeply inspire us. The ideology "To value morality above benefit" and "self-sacrifice for a noble cause" in Confucian ethics intensely rebut the evil phenomena in current sports circle, which makes the participants of competitive sports behave in an appropriate manner. It plays a positive role in improving interpersonal relations in competitive sports and ensuring a successful and health development of competitive sports. Moral cultivation is a kind of self-reform and selfimprovement in moral quality, and is in fact the reflection of conflicts and combats of two or more forces in people. Therefore, the sports moral cultivation process is also the process of self-discipline ideology struggle, in which people constantly use good to fight against evil, and right against wrong, for the purpose of unceasingly perfection in morality to purify the whole sports environment. At this point, the Confucian ideology and sayings of emphasis on morality and cultivation present a reference meaning to modern sports moral cultivation.

\section{Consideration of Educational Reform in College Sports, and the Emphasis on Psy- chological Guidance in Sports Education}

In light of the features in learning motor cognitive style through motor skill, sports learning is characterized by autonomy, experience, exploration and cooperation. 
While from the goal of subject teaching, sports leaning does not just involve mastering of motor skill, as in "Reform the trend of courses overemphasizing the knowledge imparting, and highlight the formation of positive and active learning attitude with a view to making the basic knowledge and skills acquisition process also become a process of learning to study and form correct values.” proposed in the Basic Education Curriculum Reform Outline (Pilot version) to emphasize the educational goals of subject teaching. However, discussion about educational goals without sports and health courses will be void and meaningless.

In fact, to master the features of motor skill learning patterns in sports subject teaching is equal to actually master the educational features and opportunities of sports and health courses. With the motor skill learning experience, it may be extended from cognitive field to other field such as method, emotion, attitude and values, and thus makes the learning process not only of increasing knowledge and skills, but also of minds and sound personalities development; With the motor skill learning autonomy, the initiative, independence and selfcontrol will be highlighted to form a high-quality learning process, which carries forward students subjectivity and independent spirit; With the motor skill learning exploration, innovation consciousness and autonomic learning abilities of students will be subtly developed; With the motor skill learning cooperation, the democratic, equal, cooperative, positive, harmonious and common studying academic atmosphere and social psychological quality of mutual credits and cooperation will be formed.

While in the current reform practice of sports and health courses, the sports skills learning are often excluded for highlighting the new learning methods: To emphasize autonomic experience, it will exclude the leading role of teachers, and it is much more so for the new "sheep herding style" teaching compared to the past; To reflect the exploration, discussions and questionings are impractically performed in teaching activities, which lack the values thinking of process itself, and are just the formal applications of new teaching methods; To show its cooperation, each course is made into a game, which loses the due nature of sports teaching in educating students about social psychological qualities. Teaching process appears to be active and lively, and students are happy about that but gain nothing. After the whole exciting sports activities, we have to consider: What is the value specialty for the existence of sports as a subject?

Sports teaching methods shall transform the biased thoughts of "Cognition and sports skills only" into knowledge and skills learning, as well as an all-round training of emotional attitude and personality spirit, which indicates a diversified combination of sports learning patterns. Based on the previous findings and inventions of effective sports learning patterns, it strictly utilizes the educational features and goals of sports subject to give autonomy, experience, exploration and cooperation features to many different sports learning methods such as games, practices, matches, experience and inspiration. Any discussion about the change trend of learning method without its subject and cognitive goal will finally lessen the comprehensive educational functions of the subject, and violate the subject reform purpose.

\section{Conclusion}

Confucian focused on humanized nature and humanities values. Once this mind vision enters the sports field, the sports view having oriental humanity spirit will be naturally produced, which sees sports as an educational way of improving people's mental shackles, and by happiness gained in sports activities to covertly and eventually achieve a healthy personality with harmonization between soma and spirit. The sports ideology of Chinese sports under the influence by Confusion culture lays emphasis on integration and combination of mind and body, as well as the moral cultivation; and focuses on morality and artistry in sports functions and forms for the purpose of shaping the unification of social value and class nature for sports; In terms of sports development, it has the theory and practice of qi circulation to achieve spiritual transcendence.

These positive factors provide modern sports development with developing opportunities. Meanwhile, they reform the relatively weaker sports policies and organizations based on market economy development to increase efforts in sports and legal construction, harmonize the relations between sports law and rules and regulations of sports departments, propel modern sports to achieve the confirmed harmonious value, give priority to harmony and emphasize the directional development of social responsibility. By sourcing the sports and taking into account the time conditions, its research will forcefully and internally promote the development of modern sports.

\section{References}

[1] Yu Kehong. Jin Fuchun . Introduction to Sports Culture [M]. Beijing: Higher Education Press, 2004, 44

[2] Hua Hongxing. Sports Ethics[M]. Nanjing: Hohai University Press , 1999, 83

[3] He Yongchao. Sports Theory Course [M]. Beijing: Beijing Sport University Press, 2004, 40

[4] Zhao Hongen, Li Baoxi. Introduction of Chinese Traditional Culture[M]. Shanghai: Peoples Publishing House, 2003

[5] Confucius - The Analects • The History of Chinese Confucianism[M]. Hebei: Hebei University Press, 1986

[6] Writing Group of Sports History Textbooks. Sports History [M]. Beijing: Higher Education Press, 1996

[7] Shan Qinghua. The Influence of Confusion Culture on Chinese Ancient Sports Development and the Research on Modern Value[J]. Sports and Science, 2007

[8] [8] Fu Jian. The Change in Sports Cognitive Style and Learning Methods[J]. Sports and Science, 2007

[9] Liu Qiangde. Restricted View about the Influence of Confusion Culture on Chinese Ancient Sports Development and Modern Value[J]. Sports Culture Guide, 2006

[10] Liu Ying. The Influence of Traditional Culture on Chinese Ancient Sports Development and the Research on Modern Value[J]. Shandong Sport Science and Technology, 2007

[11] Jiang Zhilan. Innovative Research on Moral Thought of Ancient Sports and its Inheritance[J]. Southwestern University, 2007 